\title{
Influence of Annealing Conditions on Magnetic Properties and Phase Constitution of the Rapidly Solidified $\mathrm{Fe}_{65} \mathrm{Pr}_{9} \mathrm{~B}_{18} \mathrm{~W}_{8}$ Alloy Ribbons
}

\author{
K. Filipecka ${ }^{a, b *}$, P. PAWliK ${ }^{a}$, A. Kozdraś ${ }^{c}$ And J. Filipecki ${ }^{b}$ \\ ${ }^{a}$ Institute of Physics, Faculty of Production Engineering and Materials Technology, \\ Częstochowa University of Technology, al. Armii Krajowej 19, 42-200 Częstochowa, Poland \\ ${ }^{b}$ Institute of Physics, Faculty of Mathematics and Natural Science, Jan Długosz University, \\ al. Armii Krajowej 13/15, 42-200 Częstochowa, Poland \\ ${ }^{c}$ Department of Physics, Faculty of Production Engineering and Logistics, Opole University of Technology, \\ Ozimska 75, 45-370 Opole, Poland

\begin{abstract}
In the present work, the influence of annealing conditions on magnetic properties and phase constitution of the rapidly solidified $\mathrm{Fe}_{65} \mathrm{Pr}_{9} \mathrm{~B}_{18} \mathrm{~W}_{8}$ alloy ribbons, were investigate. Samples were prepared by arc-melting of high purity constituent elements under the Ar atmosphere. Ribbons were obtained by melt-spinning technique under low pressure of Ar. The ribbons in as-cast state had amorphous structure and soft magnetic properties. Heat treatment, carried out at various temperatures (from $923 \mathrm{~K}$ to $1023 \mathrm{~K}$ ) for $5 \mathrm{~min}$, resulted in an evolution of the phase constitution that caused changes in magnetic properties of the alloy. The crystallization behavior was studied using differential scanning calorimetry and X-ray diffractometry. The room temperature magnetic properties were determined from hysteresis loops measured by VSM magnetometer in the external magnetic field up to $2 \mathrm{~T}$.
\end{abstract}

DOI: $10.12693 /$ APhysPolA.129.185

PACS: $75.50 . \mathrm{Ww}, 75.50 . \mathrm{Kj}, 71.20 . \mathrm{Eh}$

\section{Introduction}

Rare earth-iron-boron hard magnetic materials have been the subject of intensive studies since their first announcement in 1984 [1, 2]. These materials are the precursor for fabrication of permanent magnets, which are used for a wide range of applications [3]. The most often commercially used magnets are $\mathrm{Nd}-\mathrm{Fe}-\mathrm{B}$ alloys. However, at temperatures below $150 \mathrm{~K}$ the magnetic properties of $\mathrm{Nd}_{2} \mathrm{Fe}_{14} \mathrm{~B}$ phase tend to deteriorate due to a spin reorientation effect [4]. In order to sustain the good magnetic properties at low temperatures, Pr-based alloys are considered as a potentially good candidates as alternative for $\mathrm{Nd}-\mathrm{Fe}-\mathrm{B}[5]$. As the $\mathrm{Pr}_{2} \mathrm{Fe}_{14} \mathrm{~B}$ phase has higher value of anisotropy field $(87 \mathrm{kOe})$ than that for $\mathrm{Nd}_{2} \mathrm{Fe}_{14} \mathrm{~B}$ counterpart $(67 \mathrm{kOe})$ [6], it is expected that Pr replacement will also cause the increase of coercivity field ${ }_{J} H_{\mathrm{c}}$. Such properties allow to improve the maximum magnetic energy product $(B H)_{\max }$ of magnets containing this phase [7]. All these factors cause that the $\mathrm{Pr}-$ $\mathrm{Fe}-\mathrm{B}$ magnets are attractive for applications in a wide range of temperatures [8]. Up to now, the influence of alloying on microstructure and magnetic properties have been widely studied in Pr-based magnets [9-12]. One of them, which significantly affects the microstructure of the RE-Fe-B type alloys is tungsten. Furthermore, its addition causes improvement of their glass forming

*corresponding author; e-mail: kasia.filipecka@onet.eu abilities $[13,14]$. In the present study, the influence of annealing conditions on magnetic properties and phase constitution of the rapidly solidified $\mathrm{Fe}_{65} \operatorname{Pr}_{9} \mathrm{~B}_{18} \mathrm{~W}_{8}$ alloy ribbons, were investigated.

\section{Samples preparation and experimental techniques}

The $\mathrm{Fe}_{65} \mathrm{Pr}_{9} \mathrm{~B}_{18} \mathrm{~W}_{8}$ base alloy was prepared by arcmelting of high purity constituent elements with addition of pre-alloy $\mathrm{Fe}-\mathrm{B}$ of known composition. The ingot samples were re-melted several times under an Ar atmosphere in order to get homogeneity. Subsequently, the ribbon samples were produced by melt-spinning technique under the Ar atmosphere at linear speed of the copper roll surface of $25 \mathrm{~m} / \mathrm{s}$. The rapidly solidified samples were sealed off in the quartz tubes under low pressure of the $\mathrm{Ar}$ and subjected to annealing for $5 \mathrm{~min}$ at the temperatures ranging from $923 \mathrm{~K}$ to $1023 \mathrm{~K}$. Crystallization behavior of the as-cast ribbon was studied using differential scanning calorimeter Netzsch DSC404 at heating rate of $10^{\circ} \mathrm{C} / \mathrm{min}$. The X-ray diffraction (XRD) scans were measured using Bruker D8 Advance diffractometer with $\mathrm{Cu} K_{\alpha}$ radiation. The ribbons were crushed to powder in order to obtain a specimens representative for the entire volume of the material. Magnetic properties were examined using LakeShore 7307 vibrating sample magnetometer at external magnetic fields up to $2 \mathrm{~T}$ at room temperature. 


\section{Results and discussion}

In order to analyze the crystallization behavior, the DSC curve of as-cast amorphous ribbon was measured at a heating rate of $10 \mathrm{~K} / \mathrm{min}$ (Fig. 1). It was shown that the crystallization process proceeds through two steps corresponding to exothermic peaks on DSC curve. The glass transition temperature $T_{\mathrm{g}}$ of $760 \mathrm{~K}$, crystallization temperatures $T_{\mathrm{x}_{1}}$ of $920 \mathrm{~K}$ and $T_{\mathrm{x}_{2}}$ of $1020 \mathrm{~K}$, and supercooled liquid region before crystallization $\Delta T_{\mathrm{x}}$ of $100 \mathrm{~K}$, were determined from this curve. The DSC studies were used to specify the region of annealing temperatures during heat treatment.

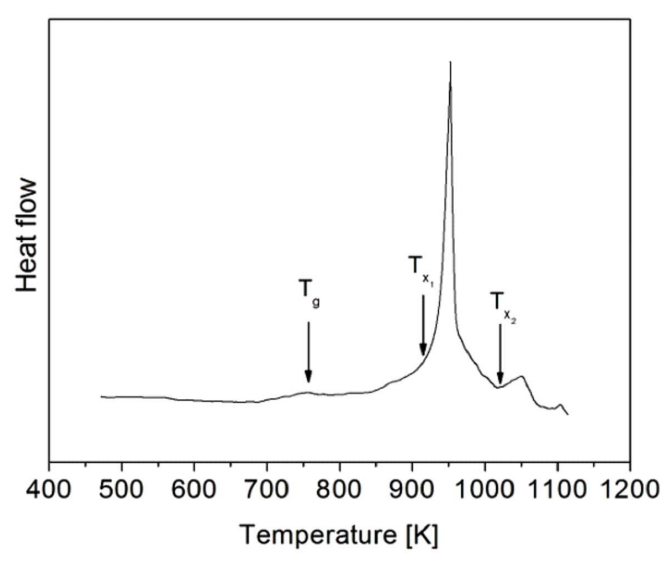

Fig. 1. DCS curves of melt-spun $\mathrm{Fe}_{65} \mathrm{Pr}_{9} \mathrm{~B}_{18} \mathrm{~W}_{8}$ ribbons measured at a heating rate of $10 \mathrm{~K} / \mathrm{min}$.

The XRD scans measured for ribbon in as-cast state and those subjected to annealing at temperatures from $923 \mathrm{~K}$ to $1023 \mathrm{~K}$ for $5 \mathrm{~min}$ are shown in Fig. 2. For both: as-cast sample and those subjected to annealing at $923 \mathrm{~K}$, a wide bump in the $2 \Theta$ range between 35 and $50 \mathrm{deg}$ were observed. Annealing at $943 \mathrm{~K}$ and higher temperatures resulted in slight modification of the phase constitution. The phase analysis of ribbons annealed at this temperature range indicates presence of hard magnetic $\operatorname{Pr}_{2} \mathrm{Fe}_{14} \mathrm{~B}$ and the paramagnetic $\operatorname{Pr}_{1+x} \mathrm{Fe}_{4} \mathrm{~B}_{4}$ phases. Also the peaks corresponding to non expected hard magnetic $\operatorname{Pr}_{2} \mathrm{Fe}_{14} \mathrm{C}_{0.95} \mathrm{~B}_{0.05}$ phase was identified. Carbon present in the alloy composition was not intentionally added to the alloy, but came from the rubber seals in the arc-melting furnace used for synthesis of the ingot samples. Such seal decomposes and carbon evaporates at high temperatures [15]. Annealing at higher temperatures resulted in the increase of peaks intensities, however no change of their angular positions were observed. This suggests that heat treatment at temperatures higher than $923 \mathrm{~K}$ causes growth of nanocrystals of identified phases at expense of amorphous matrix.

The hysteresis loop of selected samples are shown in Fig. 3. Soft magnetic properties of both as-cast ribbon and this annealed at $923 \mathrm{~K}$ confirm their amorphous structure. It also suggests that the annealing temperature $923 \mathrm{~K}$ is too low to obtain a crystalline

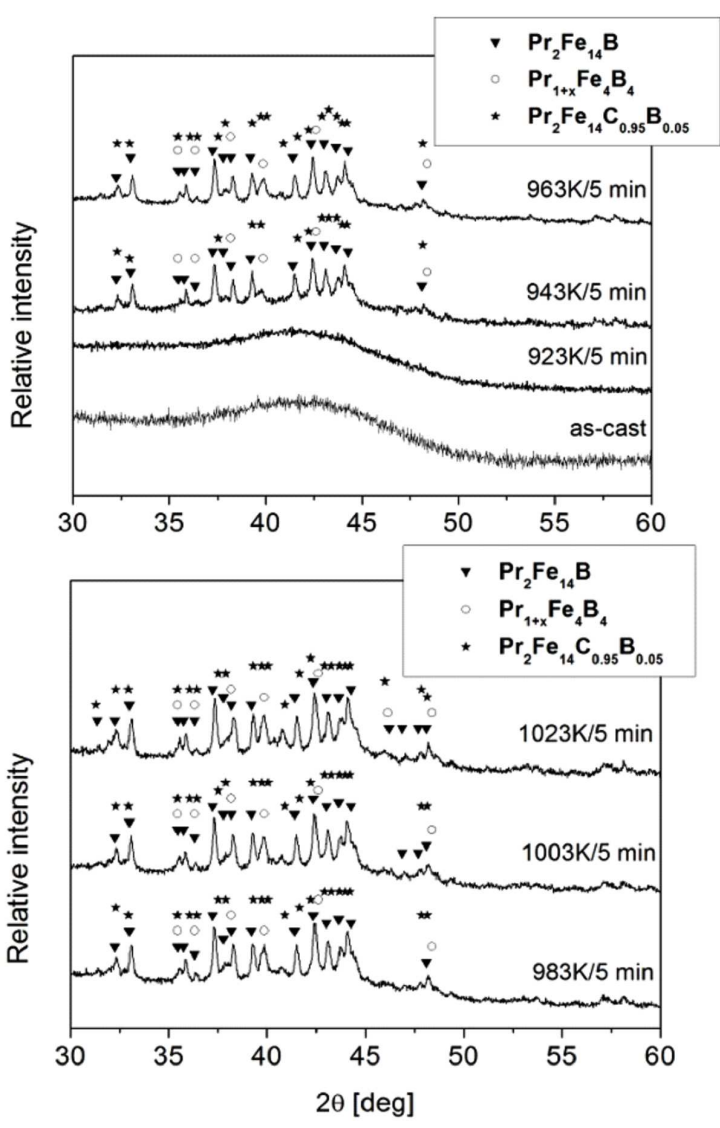

Fig. 2. The X-ray diffraction patterns for rapidly solidified $\mathrm{Fe}_{65} \mathrm{Pr}_{9} \mathrm{~B}_{18} \mathrm{~W}_{8}$ alloy ribbons in the as-cast state and subjected to annealing at various temperatures.

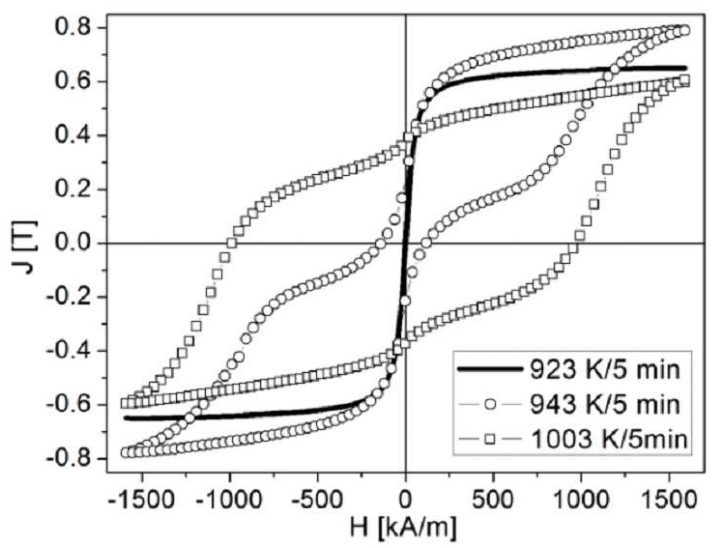

Fig. 3. The selected hysteresis loops of rapidly solidified $\mathrm{Fe}_{65} \mathrm{Pr}_{9} \mathrm{~B}_{18} \mathrm{~W}_{8}$ alloy ribbons.

microstructure. The wasp-waisted shape of hysteresis loop measured for ribbon annealed at $943 \mathrm{~K}$ is typical for alloys, where formation of isolated grains of hard magnetic phase within the amorphous matrix occurs during heat treatment. With the increase of annealing temperature hysteresis loop characteristic for hard magnetic materials were measured, which is related to evolution of microstructure and phase constitution of the 
samples. Large volume fraction of the paramagnetic $\mathrm{Pr}_{1+x} \mathrm{Fe}_{4} \mathrm{~B}_{4}$ phase and change of the chemical composition of the amorphous matrix result in relatively low values of $(B H)_{\max }$.

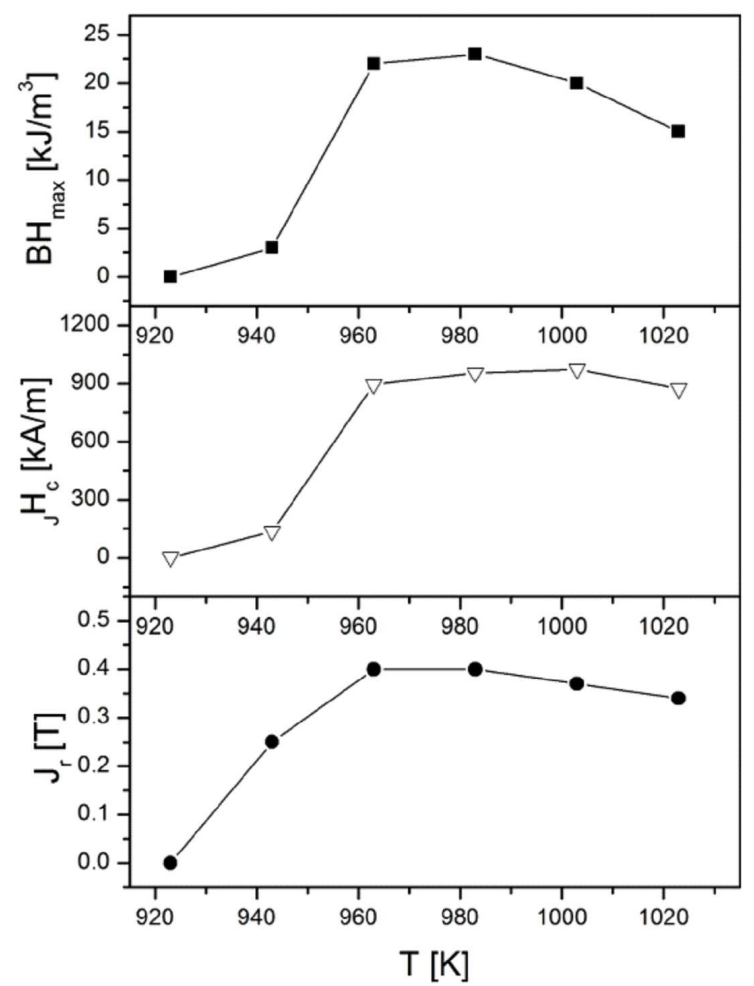

Fig. 4. Remanence $J_{\mathrm{r}}$, coercivity ${ }_{J} H_{\mathrm{c}}$ and maximum energy product $(B H)_{\max }$ vs. the annealing temperature $T$ measured for ribbons of the $\mathrm{Fe}_{65} \mathrm{Pr}_{9} \mathrm{~B}_{18} \mathrm{~W}_{8}$ alloy.

The influence of heat treatment on magnetic parameters of ribbons was shown in Fig. 4. The increase of coercivity and polarization remanence was observed for samples annealed at $963 \mathrm{~K}$. The heat treatment at higher temperatures led to continuous increase of remanence and almost constant coercivity values.

\section{Conclusion}

The paper presents the structural and magnetic studies on melt-spun $\mathrm{Fe}_{65} \mathrm{Pr}_{9} \mathrm{~B}_{18} \mathrm{~W}_{8}$ alloy ribbons. The XRD studies have shown that as-cast ribbon had amorphous structure. Annealing temperature of $923 \mathrm{~K}$ was too low to obtain nanocrystalline microstructure and change magnetic properties. X-ray diffraction patterns of annealed at $943 \mathrm{~K}$ and higher temperatures revealed a presence of the hard magnetic $\operatorname{Pr}_{2} \mathrm{Fe}_{14} \mathrm{~B}$ and $\mathrm{Pr}_{2} \mathrm{Fe}_{14} \mathrm{C}_{0.95} \mathrm{~B}_{0.05}$ and the paramagnetic $\operatorname{Pr}_{1+x} \mathrm{Fe}_{4} \mathrm{~B}_{4}$ phases. With increase of annealing temperature an increase of magnetic parameters was observed. Presented results suggest that increase of annealing temperature inhibited growth of $\mathrm{Pr}_{2} \mathrm{Fe}_{14} \mathrm{~B}$ phase and resulted in refinement of microstructure of specimens. However, relatively low values of $(B H)_{\max }$ measured for annealed samples are related to high volume fraction of paramagnetic $\operatorname{Pr}_{1+x} \mathrm{Fe}_{4} \mathrm{~B}_{4}$ phase. Therefore further modification of the alloy compositions, that would improve the magnetic properties and allows to control the crystallization process have to be done.

\section{References}

[1] J.J. Croat, J.F. Herbst, R.E. Lee, F.E. Pinkerton, J. Appl. Phys. 55, 2078 (1984).

[2] M. Sagawa, S. Fujimura, N. Togawa, H. Yamamoto, J. Appl. Phys. 55, 2083 (1984).

[3] R. Skomski, J.M.D. Coey, Permanent Magnetism, Taylor \& Francis Group, New York 1999.

[4] D. Givord, H.S. Li, R. Perrier de la Bathie, Solid State Commun. 51, 857 (1984).

[5] E.B. Boltich, E. Oswald, M.Q. Haung, S. Hirosawa, J. Appl. Phys. 57, 4106 (1985).

[6] S. Hirosawa, Y. Matsuura, H. Yamamoto, J. Appl. Phys. 59, 873 (1986).

[7] D.H. Ping, T.S. Xie, D.X. Li, H.Q. Ye, Nanostruct. Mater. 5, 457 (1995).

[8] J.F. Herbst, J.J. Croat, J. Magn. Magn. Mater. 100, 57 (1991).

[9] P. Pawlik, H.A. Davies, Scr. Mater. 49, 755 (2003).

[10] H.W. Chang, C.H. Chiu, C.W. Chang, C.H. Chen, W.C. Chang, Y.D. Yao, A.C. Sun, J. Alloys Comp. 407, 53 (2006).

[11] P. Pawlik, K. Pawlik, J.J. Wysłocki, W. Kaszuwara, J. Ferenc, J. Alloys Comp. 536, S342 (2011).

[12] A.D. Barra-Barrera, A.M. Pizzo, V. Villas-Boas, J. Magn. Magn. Mater. 302, 68 (2006).

[13] K. Filipecka, K. Pawlik, P. Pawlik, J.J. Wysłocki, P. Gebara, A. Przybył, Acta Phys. Pol. A 126, 164 (2014).

[14] A. Przybył, J.J. Wysłocki, J. Mater. Process. Technol. 175, 352 (2006).

[15] K. Pawlik, EPJ Web Conf. 40, 06004 (2013). 